\title{
A Research on Microgrid Technology by Non Conventional and Renewable Sources
}

\author{
M. Anjalakshi, S. Pavithra, M. Moovendan, P. \\ Srinivasan
}

\begin{abstract}
Microgrid are little gathering of interconnected power age in charge innovations that can work inside or free of a focal matrix, genuine aggravations and expandingsystem unwavering quality.Distributed resources can give capacity to local loads in the electric distribution system just as advantages, for example improve unwavering quality.Microgrid are capable of operating in grid tied mode and islanded mode.An ideal power system is utilized to decide the ideal allotment of assets utilizing a tranformative programming stratergy,acomplishing the most the minimal expense of providing the interest while representing physical activity.

Index terms--- Microgrid, Renewable Resources.
\end{abstract}

\section{INTRODUCTION}

The need to assorted variety vitality sources, vitality self rule and vitality efficency the infilteration of distributed generation from renewable sources like solar and wind is quickly expznding as the patern moves from sustained unified power stations towards progressively fit power transmission on the electricity grid .

At the point when low voltage distributed power capacity acomplishes a high extend to a specificto be specific high permiability,the acknowledgment of parity of circulation arrange control and the unwavering quality of high power supply will be very difficult .The improvement of microgrid to certain extend determines the application size of renewable energy. In this paper the development of microgrid is briefly studied.

\section{BASIC CONCEPTS}

Microgrid (MG ) is a solitary controlled unit in a power system that can be worked as a solitary agregated load. The unit is comprised of generaters energy storage load controller and power elecrtonic interfaces like inverters. The MG has to basic segment a static switch and a smaller scale source which comprises of generator storage and an invertor.IEEE 1547 standard sets down program tripping of the interconnected generators of a power system.

The CERTS specificaly consortium for electric reliability, technology solution first put forward the idea of microgrid in 2001. Our country advances the idea of "microgrid in a micro network technology system search" work concerns held by the state grid electric power research institute in

Revised Version Manuscript Received on August 19, 2019.

M. Anjalakshi, Student, Department of Electrical and Electronics Engineering, SRM Institute of Science and Technology.Chennai, T.N, India (e-mail: Atchuanju3499@gmail.com)

S. Pavithra, Student, Department of Electrical and Electronics Engineering, SRM Institute of Science and Technology. Chennai, T.N, India(e-mail: spavithra028@gmail.com)

M. Moovendan, Assistant Professor, Department of Electrical and Electronics Engineering, SRM Institute of Science and Technology. Chennai, T.N, India(e-mail: moove86@gmail.com)

P. Srinivasan, Assistant Professor, Department of Electrical and Electronics Engineering, SRM Institute of Science and Technology. Chennai, T.N, India(e-mail: srinivasp808@gmail.com)
2009 , microgrid is a little secluded, decentralized energy supply network based on distributed power generation with the subject of decentralized resources joined with poer quality management an energy utilizationtechnology.

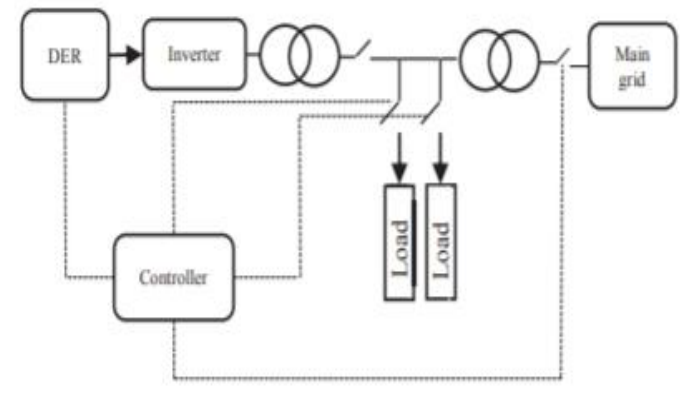

Fig. 1: Basic Micro Grid Circuit

\section{TYPES OF MODE}

\section{Grid connected mode}

It is a ordinary working method of a MG with no power quality disturbance on the main grid to which it is associated. In this mode the MG may take into account its whole local loads or may either import or export poer to the main grid depending on the total ower generation to the nearby DG.

\section{Islanded Mode}

It is a condition in which a distributed generate( DG) continous to power a location even though electric grid power is no longer present.

\section{CHARACTERISTICS OFMICROGRID}

Flexibility: As defined in the paper the microgrid can run in both isolated network and grid connected network. The grid connected mode acts as a normal operation in which display the system can either obserbe power from the grid network or supply.power to the main network. At the point when something happens to the network the microgrid disconnect the connection with thw main network turning of the boundary switch and transform into detached system rate.

Compatability: Microgrid is the best method to accomplish the association of distributed energy. It coordinates the unique distributed energy and balances out the power supply further most, balance among free market activity through distributed energy and control assurence which successfully survive the hazards of distributed energy and take care of the issue when microgrid connects to the bulk grid. 
Economy: Microgrid access to huge measure of renewable energy which implies we can distribute the output of different microsource ideally. Further more consolidating the microgrid with medium size heat supply can reduce the change of various energy and improve energy efficiency, advance the energy structure so as to accomplish.

\section{TECHNOLOGY OF MICROGRID}

Activity microgrid framework cannot be discrete from innovation that help from each part that make up the microwave matrix system, as the wellspring of vitality, interconnected switches and microgrid control freamework. Technologies in energy sources distributed generation includes the utilization of renewable energy sources such as photovoltaic, wind turbines and fuel cells . Technology in energy storage microgrid system which include battery, supercapacitor and flywheels.

\section{IMPORTANCE OF MICROGRID}

a. Normal power supply to the MG area is maintained during natural disasters, blackouts, etc...

b. Cost for per unit of energy is greatly reduced by setting up a MG with localy available renewable energy source in the remote locations

c. MG utilise mostly renewable ecofriendly technologies for power generation.

d. The power generations will have zero emission.

e. Reliability and quality of power received by a customer is greatly enchansed by setting up a MG

\section{CLASSIFICATION OFMICROGRID RESULTS}

Based on the nature of output voltage,MGclassified into (1) AC MG (2) DC MG

\section{A .AC Microgrid}

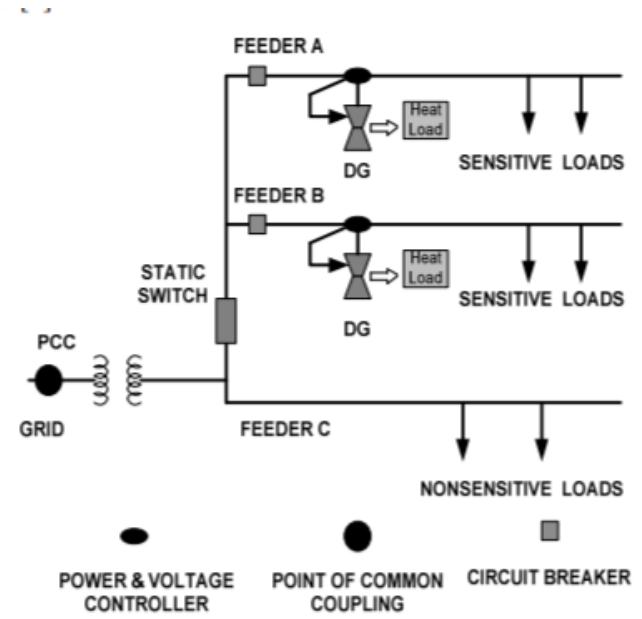

Fig. 2: AC Micro Grid

A MG consists of cluster of loads, distributed generators, some energy storage system and is also connected with the utility grid. some of the energy sources, which qualify for DER like fuel cells, PV units Microcontroller etc... produce DC output or produce electric output at frequencies not compatible with the grid frequency. The MS such as photovoltaic or fuel cell generate output often at variable frequencies.
Microturbines create voltage at higher than matrix frequencies. As prescribes for CERTS in icroGrid.

At the point when a few DRs are accessible on a MS the yield of every convertor is associated in parallel and controlled to create a similar dimension of the voltage, generating transport.

The circulation framework is comprised of radical feeders A,B where the senaitive burdens are associated on feeder . The feeder $\mathrm{C}$ has non touchy burdens and which are not influenced by power quality occasions on the network.

The MG can operate in two modes gridconnected mode and islanded mode. In the grid connected mode the MG supports the utility grid while exchanging power with it. In this mode the frequency of MG is maintained by the utility grid. The utility grid and its required to control the amount of harmonics and dc injected into the grid at the PCC.

In the island of activity,the interconnections with primary matrix is associated mode, the MG either attracts or supplies capacity to the fundamental grid, depending on the age and burden blend and market approches..

\section{B. DC Microgrid}

With the coming of semiconconductors gadget, there has been an unrest in the realm of hardware gadges over the most recent couple of decades. A large portion of the home use apparatuses telephones,laptops,ipods and so on .. Use dc control either from a battery or after correction of the air conditioner source. Each of them has a connector or charge the battery. Thus DC microgrid turned into a plausibility of a low voltage bipolar DC microgrid.

\section{CONTROL AND MANAGEMENT OFMICROGRID}

1. Relentless state and dinamic attributes of microgrid unique in relation to regular plants..

2. Microgrid has innate uneven burden because of one stage load.

3. The supply of intensity from microgrid can emerge out of un controlled source, for example, wind .

4. The job vitality stockpiling is extremely.

5. Microgrid accomodate dis substantial in the control instrument utilized.

6. Microgrid requires initialy requirement of intensity quality or administration inclinations for specific sorts of burdens.

\section{MICROGRID ASSOCIATEDTECHNOLOGY}

Microgrid can be considered as a little age usage system, which has control assets and loada inside the framework. Inany case it isnot as basic as a of the key specialized necessities on different parts of its arranging and configuration, request and supply balancing, protection confounded and setting, and so forth. They include:

a. Utilization of appropriated age sources,including sustainable and CHP generatorsuse of multiple invertres. 
b. ability to island the system

c. multiple operation modes, such as integreted operation is landed operation, integration transition

\section{MICROGRID AND SMALLGRID}

a. There are regularly perplexity on the definition and extents of microgrid and brillint grid, which isnot right. In spite of the fact that microgrid may join many keen lattice features, the key refinements of a microgrid. be close to cutomers

b. heavily use of power electronics,such as inverter.

c. be able to fully separate from the main grid and operate independently.

\section{TECHNICAL CHALLENGESON MICROGRID}

As a new paradigm of power system, implementation of microgrid still face many obstacles. Less understanding about microgrid and unfavorable government policies become an obstacles in applying microgrid technology. In general, in addition can be applied as a solution to electricity in remote areas,microgrid technology can also be used as electrical solutions such as urban residential complexes,offices, schools and others. In which implementation of microgrid technology will provide advantages compared if have to build a new transmission and distribution network.

\section{ADVANTAGESOF MICROGRID}

a. Microgrid, have ability, during a utility grid disturbance, to separate and isolate itself from the utility seamlessly with little or no disruptionto the loads within the Microgrid.

b. In peak load periods microgrid can prevents utility grid failure by reducing the load on the grid

c. Microgrid have environmental benefits made possible by use low or zero emission generators.

d. In microgrid to increasing energy efficiency, the use of both electricity and heat is permitted to get closer the generator to user

e. microgrid can act to mitigate the electricity costs to its users bygenerating some or all of its electricity needs.

\section{DISADVANTAGES OF MICROGRID}

a. In microgrid, that must be considered and controlled voltage, frequency and power quality parameters to acceptable standards whilst the power and energy balance is maintained.

b. Electrical energy needs to be stored in battery banks thus requring more space and maintaince.

c. The difficuilty of resynchronization with the utility grid.

d. Microgrid protection is one of the most important challenges facing the implementation of microgrids.

e. Issues such as standby charges and net metering may pose obstacles for Microgrid.

\section{CONCLUSION}

With regards to the energy lag globally, microgrid excited around the world as the compelling structures to utilise distributed energy. Microgrid complies with the necessities to advance recharging renewable energy power generation and social manageable improvement and will involve an imperative position in the advancement of development of network.

\section{REFERENCES}

1. Ramakumar R. Role of distributed generation in reinforcing the critical electric power infrastructure[C]//Power Engineering Society Winter Meeting, 2001. IEEE. IEEE, 2001, 1: 139-139.

2. Wei C, Jing S, Li R, et al. Composite usage of muti-type energy storage technologies in microgrid[J]. Automation of Electric Power Systems, 2010, 34(1): 112-115.

3. Guo-dong W. Overview on Smart Micro-grid Research[J]. China Electric Power (Technology Edition), 2012, 2: 021.

4. Zhenjie L, Yue Y. Smart microgrid: a novel organization form of smart distribution grid in the future[J]. Automation of Electric Power Systems, 2009, 33(17): 42-48.

5. Lasseter R H, Paigi P. Microgrid: A conceptual solution[C]//Power Electronics Specialists Conference, 2004. PESC 04.2004 IEEE 35th Annual. IEEE, 2004, 6: 4285-4290.

6. Piagi P, Lasseter R H. Autonomous control of microgrids[C]//Power Engineering Society General Meeting, 2006. IEEE.IEEE, 2006: 8 pp.

7. Katiraei F, Iravani M R. Power management strategies for a microgrid with multiple distributed generation units[J]. IEEE transactions on power systems, 2006, 21(4): 1821-1831.

8. Chengshan W, Peng L. Development and challenges of distributed generation, the micro-grid and smart distribution system[J]. Automation of Electric Power Systems, 2010, 34(2): 10-14.

9. N. D. Hatziargyriou, H. Asano, R. Iravani and C. Marnay, “Microgrids,"IEEE Power Energy, vol. 5, no. 4, pp. 78-94, Jul./Aug. 2007.[10] N. D. Hatziargyriou, "Microgrids," IEEE Power Energy, vol. 6, no.3, pp. 26-29, May/Jun. 2008.

10. G. Venkataramanan and C. Marnay, "A larger role for microgrids," IEEE Power Energy, vol. 6, no. 3, pp. 78-82, May/Jun. 2008.

11. Microgrid Deployment Tracker 2Q14[Online].Available:http://www.navigantresearch.com/research/ micgrid-deploymenttracker-2q14

12. J. B. Almada, R. P. S. Leão, F. F. D. Montenegro, S. S. V. Miranda, R. F. SampaioAlmada, J.B. ," Modeling and Simulation of a microgrid with multiple energy resources, " EUROCON, 2013 IEEE, 2013, pp.1150 - 1157.

13. Qiang Fu, Montoya, L.F.,Solanki, A. ,Nasiri, A., Bhavaraju, V. Abdallah, T. ,Yu, D.C.,"Microgrid Generation Capacity Design With Renewables and Energy Storage Addressing Power Quality and Surety," IEEE Transactions on Smart Grid, vol. 3, no. 4, pp. 20192027, 2012

14. Mizani, S.,Yazdani, A.,"Design and operation of a remote microgrid "Industrial Electronics, IECON '09. 35th Annual Conference of IEEE, pp.4299 - 4304, 2009.

15. Poh Chiang Loh,D. Li ,Y. K. Chai, Blaabjerg, F., "Autonomous Control of Interlinking Converter With Energy Storage in Hybrid AC-DC Microgrid," IEEE Transactions on Industry Applications, vol. 49, no. 3, pp. 374 - 1382, 2013.

16. Y. Wang, K.T. Tan, So, P.L.,"Coordinatedcontrol of battery energy storage system in a microgrid ,"Power and Energy Engineering Conference (APPEEC), 2013 IEEE PES Asia Pacific , pp. 1-6, 2013.

17. Ustun, T.S., Khan, R.H., Hadbah, A., Kalam, A.,"An adaptive microgrid protection scheme based on a wide-area smart grid communications network ," 2013 IEEE Latin America Conference on Communications (LATINCOM), pp.1-5, 2013.

18. Y. J. Reddy, Y. V. P. Kumar, A. Ramsesh, S. Dash and K. P. Raiu, " Monitoring and power scheduling of a microgrid with distributed real time controllers in dynamically simulated environment, " 2012 IEEE Fifth Power India Conference, pp.1-6, 2012.

19. F. Katiraei and M. R. Iravani, "Power Management Strategies for a Microgrid WithMultiple Distributed Generation Units," IEEE Transactions on Power Systems, vol. 21, no. 4, pp.1821-1831, Nov. 2006. 